\title{
Determination of fracture toughness parameters of concrete using compact pressure test
}

\author{
Esra TUGRUL TUNC a,* \\ a Firat University, Faculty of Engineering, Department of Civil Engineering, TR-23119, Elazig, Turkey
}

ARTICLE INFO

Article history:

Received 24 August 2017

Received in revised form 06 November 2017

Accepted 23 November 2017

\section{Keywords:}

Fracture mechanics

Fracture toughness

Compact pressure test

Concrete

\begin{abstract}
A B S T R A C T
Fractures start with the formation of cracks and occur as the cracks spread in building materials. This causes significant damage to the buildings. Fracture mechanics is a science that investigates crack behavior, crack analysis and what to do for prevention of cracks. In the present study, concrete fracture toughness parameters were investigated by compact pressure test. In this context, research and a series of experiments were conducted on fractures, types of fractures, fracture mechanics, and compact pressure test. In the present empirical study, 5 unnotched and 15 notched, a total of 20 samples were used. $40 \mathrm{~mm}$ notches were created on notched samples. Cube splitting experiments were conducted using $10 \mathrm{~mm}$ wide strips on unnotched samples. For Type-I, Type-II and Type-III that were used in the calculation of the fracture toughness parameters of the said samples, fracture loads, tensile values and fractured sample details are presented. Since the concrete is a semi-brittle material, compact pressure samples were analyzed according to the principles of linear elastic fracture mechanics. It was concluded that the standard deviation for the critical fracture parameter $\left(K_{I c}\right)$ of the sample, which was naturally more stable than the present study, was smaller and as the structure size increased, the fracture toughness value increased as well.
\end{abstract}

\section{Introduction}

Concrete, which has been a major research topic in structural engineering for centuries, significantly influences the stability and the life of buildings. Concrete is formed by mixing cement, aggregate, water and, if necessary, certain additives homogeneously. The concrete is a composite building material, which is initially with plastic consistency and could be shaped, and in time, it solidifies and strengthens. In order to produce concrete in the desired quality and to determine the most suitable space and the rate to be used, the properties of concrete must be well known.
The concrete has a heterogeneous structure. Concrete strength is directly affected by the properties of the cement paste, aggregate and interface surfaces that form the concrete. The separate impact of these factors on strength was investigated by several researchers.

Mechanism of concrete fracture is significant especially for earthquake-resistant buildings, high cost structures exposed to the effects of climate and environmental conditions, reactors and defense industry buildings. The reason, time and place of the collapse of the buildings, and under which conditions the fractures that exist in the building structure or occur due to the collapse would expand in a stable or instable manner are closely associated with fracture mechanics

\footnotetext{
* Corresponding author.

Tel.: 05383769352

E-mail address: esratugrul@firat.edu.tr
} 
(Akkaya et al., 2003). When a load is applied, the event where the material reaches the point that it could not hold any longer and breaks is defined as fracture. The event of fracture changes based on the type of material used, the applied load, the temperature and the rate of deformation. Fracture mechanics examines the effect of imperfections such as notch, crack, and void in the material structure on the load bearing capacity and the resulting event of fracture. In order to determine fracture mechanics and fracture parameters of the concrete, concrete properties such as the type of material, aggregate volume, maximum grain diameter, water/cement ratio should be known. These properties play a significant role in the strength of concrete. In recent years, researchers focused on high strength and good performance concrete. In addition to obtaining high compressive strength concrete, the ability to produce concrete with the desired fracture energy became an important research topic in structural engineering.

The damages in buildings are caused by the fracture of the material that the building is composed of. A large part of these damages occur at an unpredictable time and due to unpredictable factors. Thus, it is necessary to design buildings that can minimize these undesirable consequences. For this purpose, it is necessary to observe well the fracture behavior in the structure, the analysis of the fracture in the material. Optimal ways of preventing cracks should be investigated. Thus, the fracture mechanics, which is significant for buildings, has attracted the interest of several scholars.

Today, with rapid advances in technology, it is possible to prevent damage such as notches, cracks, holes and capillary cavities in construction material. Thus, as the damage to the material is repaired, the strength increases and more strong buildings can be constructed. Fracture mechanics examines the behavior of structural imperfections such as cracks and voids in material under loads, and the damages that result in fractures. Linear Elastic Fracture Mechanics and Elastic Plastic (Non-Linear) Fracture Mechanics approaches are used in fracture mechanics (Sorucu, 2007).

The objective of the present study is to determine the correlation between the concrete fracture toughness parameters and the compact pressure test and to investigate the effect of the fracture on the splitting tensile strength and critical fracture parameters for different situations.

\subsection{Historical Progress in Fracture Mechanics}

Detailed research on fracture mechanics started when Galileo asked, "Why objects get broken?" (Galilei, 1933). This study shed light on the theory of size effect. Irwin (1957) expressed that energy approach was an equivalent of stress intensity, initiating a new era in fracture mechanics. Barenblatt (1959) and Dugdale (1960) emphasized that fracture occurs when a critical stress distribution is attained at the end of the crack and the critical stress intensity $\left(K_{c}\right)$ is a property of the material. Fracture mechanics was described as an approach that identifies the fracture strength based on the structural geometry of the load and erroneous components. It was stated that the fracture strength depends on the stress analysis. Certain studies approached the problem mathematically, accepting that the stress distribution in the region of fracture process at the end of the crack is a function. Since the 1980s, the development of computer processing abilities initiated the widespread use of the finite element method, approaching the problem of fracture mechanics using non-linear calculation methods. These developments have resulted in great contributions to the discovery of new methods and the studies on fracture mechanics.

\subsection{Fracture Mechanics in Concrete}

Although concrete is a composite material, its mechanical performance is not fully compatible with simple composite theory. While cement mortar and aggregate shows linear elastic tensile behavior when $80 \%$ of maximum tensile load is achieved, nonlinear elastic behavior is observed when 40$50 \%$ of the maximum concrete load is achieved. Nonlinear behavior of concrete under load can be explained by the definition of three-phase heterogeneous material, namely cement mortar, aggregate and transition phases in concrete content. The transition phase of $10-50 \mu \mathrm{m}$ in thickness found around the aggregate particles is the surface area between the cement mortar and the aggregate and is weaker than the other two phases. Although there are no cracks in the other two phases, micro-cracks can easily spread due to the high porosity and low tensile strength in the transition phase. This is a consequence of the nonlinear behavior of the concrete mix. Main factors that affect the concrete fracture parameters are the water/cement ratio, strength class, total aggregate amount, maximum aggregate diameter, aggregate type and source.

The use of fracture mechanics in the concrete building design increases structural safety and economy and is especially significant for high-strength concrete, fiber-reinforced concrete buildings, very large-scale concrete structures, prestressed structures and concrete dams (Caglar, 2014). The first detailed study that investigated concrete based on the complex internal structure, fracture mechanism and heterogeneity of concrete was conducted by Kaplan (1961). Splitting tensile test samples (such as cylinders and cubes) have been efficiently used in the fracture mechanics in recent years (Ince, 2010; Ince, 2012). The analytical and numerical studies used to determine the fracture toughness of the relevant samples show that the fracture load is highly influenced by the surface width of the applied load and sample size. (Ince et. al., 2015; Ince et. al., 2016). In their respective studies, Hilsdorf and Brameshuber (1991), Gettu et al. (1998), Rao and Prasad (2002) reported that as the compressive strength of concrete increases, fracture energy of the concrete increases as well. Gettu et al. (1998) observed that when the compressive strength was increased by $160 \%$, the fracture energy increased by $12 \%$. Jensen and Hansen (2001) observed that the fracture energy level of the concrete was dependent on the type of aggregate used and that the fracture energy was independent of the compressive strength of the concrete up to the compressive strength of $50 \mathrm{MPa}$. Based on the findings in a study by Yan et al. (2001), it was observed that the compressive strength and fracture energy were independent of each other in concrete with a 
compressive strength of $114 \mathrm{MPa}$. The researchers investigated the effect of parameters such as maximum aggregate size, aggregate amount, ratio of fine aggregate to coarse aggregate, and aggregate type on the fracture of the concrete. Fracture could be examined under three main topics based on the crystallographic structure of the fracture surface, the appearance of the fracture surface and deformation on the fracture surface (Fig. 1).

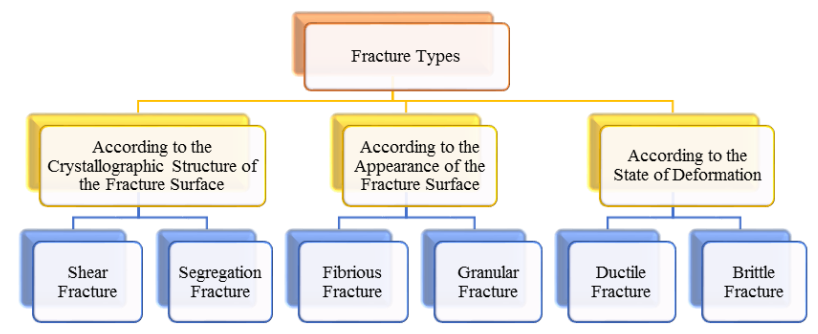

Figure 1. Classification of fracture types.

Studies on concrete fracture mechanics were generally conducted in the same direction. It is not possible to describe a heterogeneous material such as concrete with a single parameter. Thus, studies on this the have recently concentrated on the development of nonlinear methods.

\section{Determination of Fracture Toughness}

To determine the fracture toughness, first a notch is formed on the sample surface. The concrete is then subjected to a fatigue test to convert the notch to a crack. Crack formation is the main characteristic of fracture toughness tests and care must be taken to ensure that they are as smooth as possible when formed by the fatigue test. The fatigue load to be used in crack formation should be chosen so that it can form the cracks at the desired time. Very low fatigue load leads to waste of time, while a very high load causes the crack to form immediately, leading to excess plastic deformation in this region. Thus, the test results could be misleading. There is no need to create fatigue cracks on brittle material. Following the notch formation, the sample is drawn in the tensile testing device at low deformation rate. The crack progression is observed based on the applied load. As the load is increased, the material primarily undergoes elastic deformation and the size of the crack increases linearly with the increase in the load. As the load is increased, the elastic limit is exceeded and different results could be obtained depending on the fracture properties of the material. If the material is brittle, the sample breaks and the load suddenly drops when the load elastic limit is exceeded. Thus, the maximum load is taken into account when calculating the critical fracture parameter $\left(K_{I c}\right)$. If the material has a more ductile structure, the load falls when the elastic limit is exceeded and remains constant. But then, it increases and goes back to its original state. This case that is called gradual crack formation can be repeated several times until the material fractures. In $K_{I c}$ calculations, the load that caused the first crack is taken into account. When the load applied on ductile material exceeds the elastic limit, the size of the crack increases as the load increases until the material breaks. The desired value can be read using the curve obtained to calculate $K_{I c}$ (Külcü, 2015). In the Ince (2017) study, splitting strip samples having some advantages (such as compactness and lightness) compared to beams were analyzed using effective crack models. In this study, a formula for the maximum tensile strength of concrete was derived using Fourier integrals and Fourier series. $K_{I c}$ values were also determined under different conditions.

As seen in Fig. 2, the progress of the crack in concrete that contains aggregate, voids and micro-cracks is inhibited by certain mechanisms, and this leads to increased concrete toughness. Mechanisms such as aggregate at the tip of the crack acting as a crack shield by preventing the crack progress, the change in crack direction by the aggregates on its way, prevention of the crack progress by the aggregates chafing against each other, load transfer by the aggregates from one side of the crack to the other, reduction of the sharpness or forking of the crack tip due to the voids near the crack tip, result in increased concrete toughness.
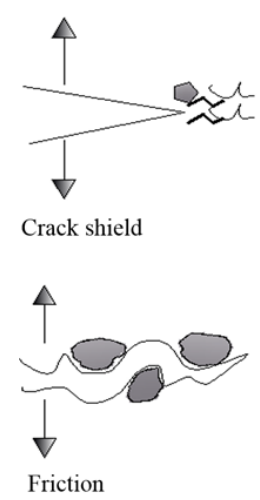
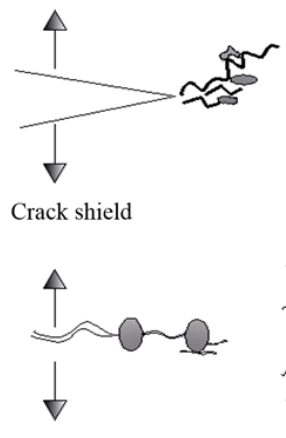

Crack bridging
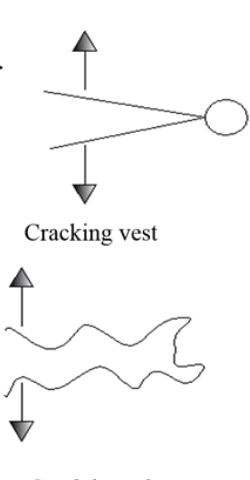

Crack branch
Figure 2. Mechanisms that cause increase in cement toughness (Akkaya, 2003).

\section{Compact Pressure Test}

In this section, the relationship between the compact pressure test and fracture mechanics was investigated and the studies conducted on this relationship were reviewed in detail.

Sabir and Asili (1996) conducted stress analyzes on fracture test samples. In this study, the effect of compact pressure test on the determination of fracture toughness of cementitious material was investigated and the stress analysis results for the test samples were evaluated. They used $100 \mathrm{~mm}$ samples with notches on their opposing surfaces. They calculated the stress intensity factor using the load applied to the samples and the finite elements method. In evaluating the results, J integral, deformation energy release rate, conical section simulation, extrapolation change were not considered. According to the researchers, fracture toughness did not demonstrate any significant changes with the change in notch 
size. They preferred the standard $100 \mathrm{~mm}$ cube samples in compressive strength tests. The cubes were precisely mounted on a horizontal machine and precisely reciprocal notches were formed with a cutting disk. The machine was pre-tuned to provide the same precision on all samples. This tuning, which was previously attempted to be performed manually, is available on the Clipper machine. Thus, the difficulties experienced during the tests were considerably reduced. In Fig. 3 (a), the test sample and load draft are presented. In Fig. 3 (b) half-sample analysis is presented.

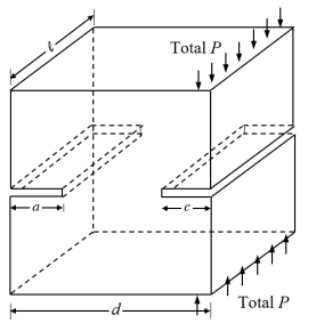

(a)

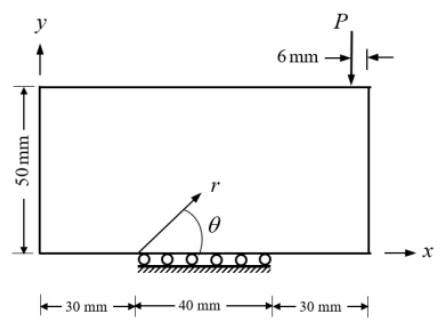

(b)
Figure 3. Compact pressure test apparatus: (a) CELL sample; (b) Analyzed half-sample (Sabir and Asili, 1996).

The test device used in the experiments had a $250 \mathrm{kN}$ load capacity and displacement control. RILEM (1985) stated that a tensile rate of $0.3 \mathrm{~mm} / \mathrm{min}$ was adequate. In this study, the tensile rate was close to the recommended value; it was 0.4 $\mathrm{mm} / \mathrm{min}$. If the load is applied far from the sample draw zone, the test fails due to cracks originating at the notch root. Due to the load configuration and its compact construction, the test samples were loaded eccentrically (CCEL) with a compact compression (Sabir and Asili, 1996).

Various finite element methods can be used to determine the stress intensity factor K. Displacement extrapolations and conic section simulation methods depend on the free crack surface displacements $\left(u_{y}\right)$ of planes with cracks. The J integral, however, is defined as an amount of energy that depends on the displacement derivatives along a path that surrounds the crack tip.

\section{Experimental Program and Results}

In the current experimental study conducted at FU Faculty of Engineering, Civil Engineering Department, Building Material Laboratory, $150 \mathrm{~mm}$ cube samples were used. The samples were poured about a year ago. Experiments were carried out with a total of 20 specimens, including 5 unnotched and 15 notched ones. The samples were notched using a mechanic machine and the notch width was $40 \mathrm{~mm}$ (Fig. 4.a). Cube splitting tests were conducted on unnotched samples. As shown in Fig. 4 (b), the load was applied through $10 \mathrm{~mm}$ wide strips. Splitting tensile strength $\left(\sigma_{N c}\right)$ was calculated with Eq. (1).

$$
\sigma_{N c}=\frac{P_{k}}{A}
$$

where; $P_{k}=$ fracture load $(\mathrm{N}), A=\operatorname{surface}$ area $\left(\mathrm{mm}^{2}\right)$.

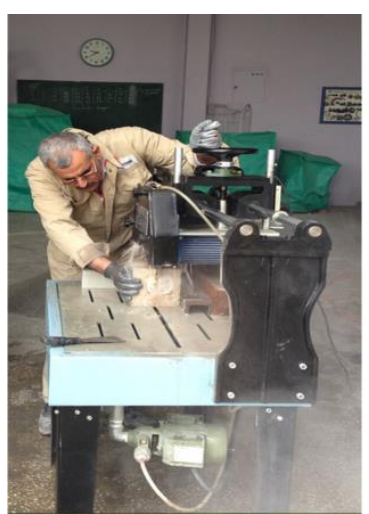

(a)

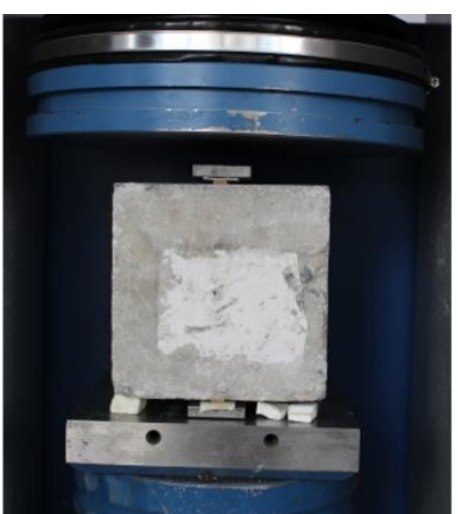

(b)
Figure 4. Experimental study: (a) Notching the samples; (b) Cube splitting test.

The variation in $\sigma_{N c}$ with $P_{k}$ for the unnotched sample is presented in Fig. 5. Accordingly, as the fracture load $P_{k}$ on the sample increased, it was observed that splitting tensile strength $\sigma_{N c}$ increased linearly as well. Examination of the figure will demonstrate that the correlation coefficient $\left(R^{2}\right)$ was very close to 1 , thus, there was a quite good fitness between $P_{k}$ and $\sigma_{N}$.

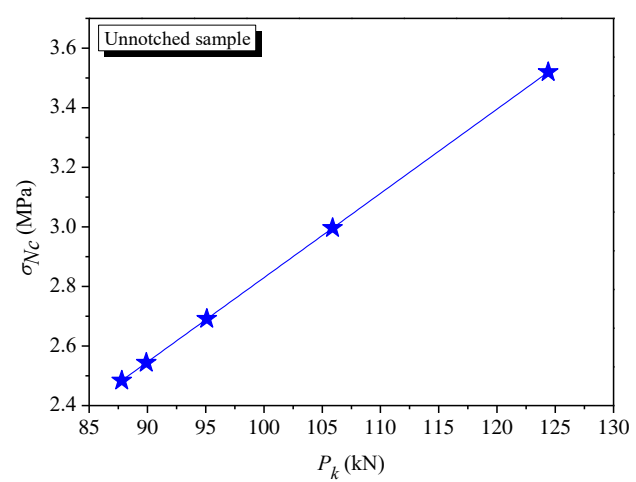

Figure 5. Variation of splitting tensile strength $\sigma_{N c}$ with fracture load $P_{k}$ for unnotched samples.

The figures on Type-I, Type-II and Type-III loads of the relevant samples are schematically shown in Fig. 6, and the images of the laboratory experiments are presented in Fig. 7. 


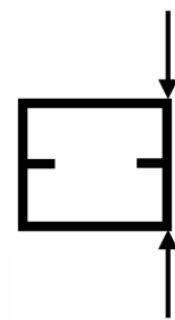

(a)

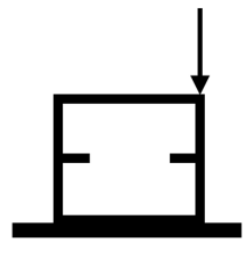

(b)

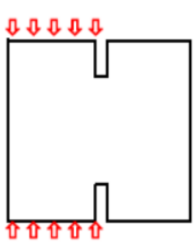

(c)
Figure 6. Schematic view of the sample load type: (a) Type-I; (b) Type-II; (c) Type-III.

The Type-I samples shown in Fig. 7 (a) were loaded with 0.1 kN/s, the Type II samples shown in Fig. 7 (b) were loaded with $0.2 \mathrm{kN} / \mathrm{s}$, and Type III samples shown in Fig. 7 (c) were loaded with $6.8 \mathrm{kN} / \mathrm{s}$. Here the relative notch size was taken as $\alpha=a / d=40 / 150=0.267$. In calculating the fracture toughness parameter in the analyzes, Eq. (2) (J-integral method) was used for Type-I and Type-II an Eq. (3) was used for Type-III. In Fig. 8, the fracture status for all sample types at the end of the experiment is presented.

$K_{I c}=\frac{P_{k}}{t d^{1 / 2}}\left[-108.1\left(\frac{a}{d}\right)^{1 / 2}+1147.1\left(\frac{a}{d}\right)^{3 / 2}-4016.8\left(\frac{a}{d}\right)^{5 / 2}+4901.1\left(\frac{a}{d}\right)^{7 / 2}\right]$

$K_{I c}=\frac{\sigma_{N c}}{4}(\pi a)^{1 / 2}$

where; $t=d=$ cube sample side length ( $\mathrm{mm}), a=$ notch width (mm).

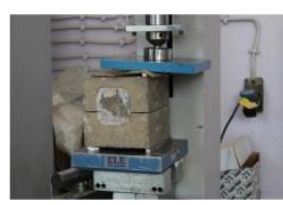

(a)

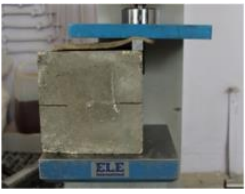

(b)

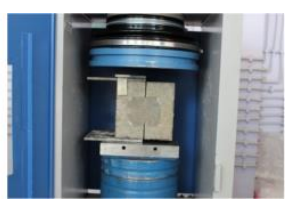

(c)
Figure 7. The moment when the samples were loaded: (a) Type-I; (b) Type-II; (c) Type-III.

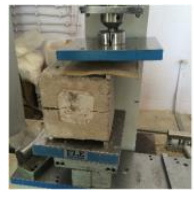

(a)

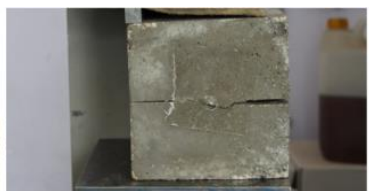

(b)

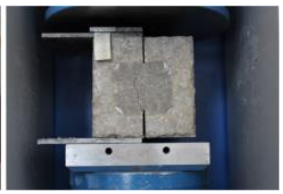

(c)
Figure 8. The moment of fracture at the end of the experiment: (a) Type -I, (b) Type -II, (c) Type -III.
The analysis results are presented in Table 1. Critical fracture parameter $\left(K_{I c}\right)$ was determined based on the fracture load $\left(P_{k}\right)$ in experiments conducted for notched Type-I, Type-II and Type-III.

Table 1. Notched compact pressure test results.

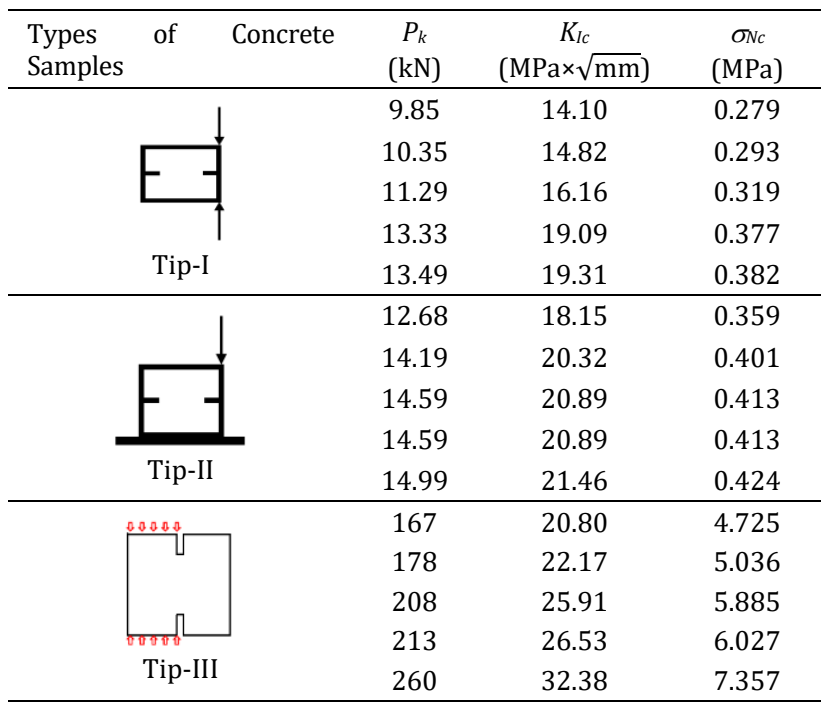

It was observed in Fig. 9 that there was a linear increase between $P_{k}$ and $K_{I c}$ for Type-I, Type-II and Type-III cases. As $P_{k}$ increased, it was observed that the $K_{I c}$ increased as well. In Fig. 9 (c), larger fracture loads were measured and higher $K_{I c}$ values were obtained when compared to others. This difference was considered to be due to the loading pattern. As a result, The Type-II $K_{\text {Ics }}$ were $22 \%$ higher than that of Type-I on average, the Type-III $K_{\text {Ics }}$ were $53 \%$ higher than that of Type-I on average, and Type-III $K_{\text {Ics }}$ were $26 \%$ more than that of Type-II on average.

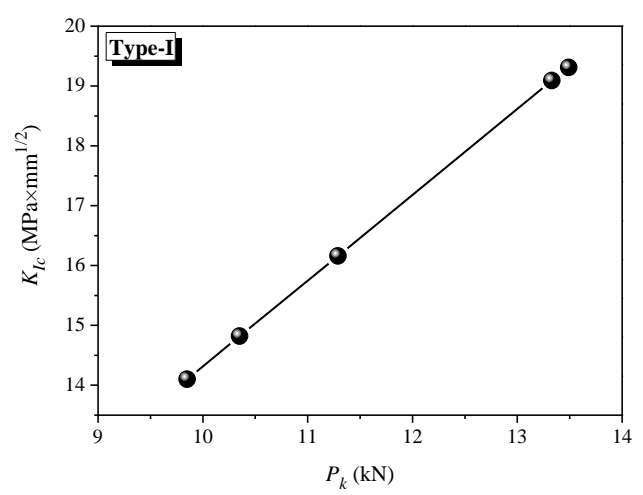

(a) 


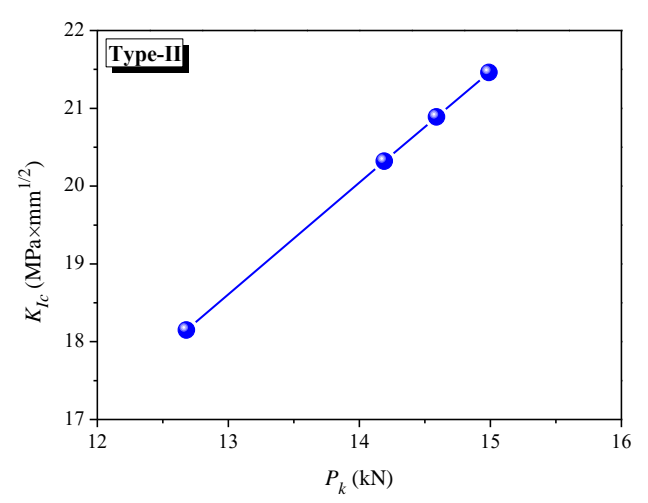

(b)

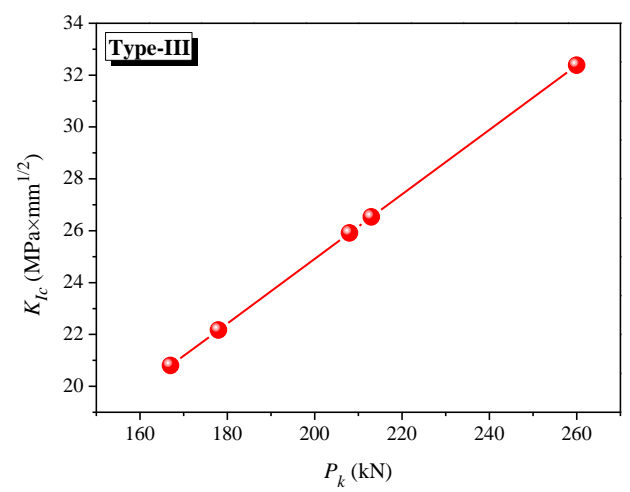

(c)

Figure 9. Variation of $K_{I c}$ with $P_{k}$ for notched samples: (a) Type-I; (b) Type-II; (c) Type-III.

In Fig. 10, it was observed that there was a linear increase between $P_{k}$ and $\sigma_{N c}$. In Fig. 10 (c) it was observed that both $P_{k}$ and $\sigma_{N}$ values were significantly higher than others.

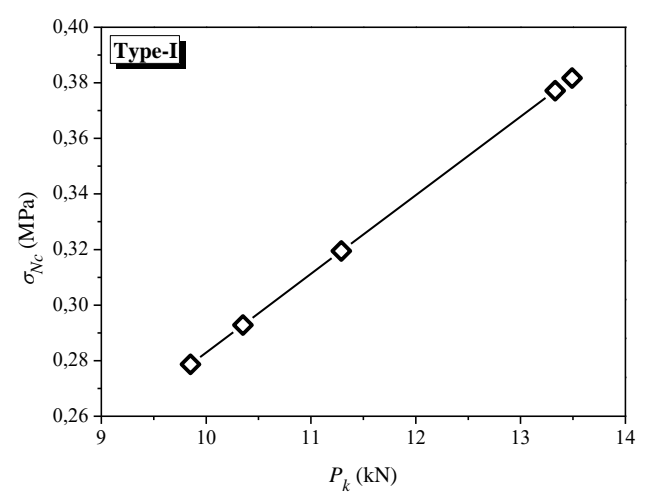

(a)

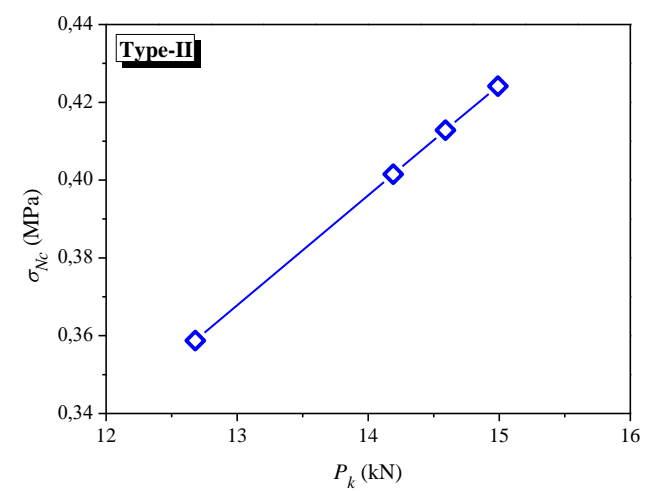

(b)

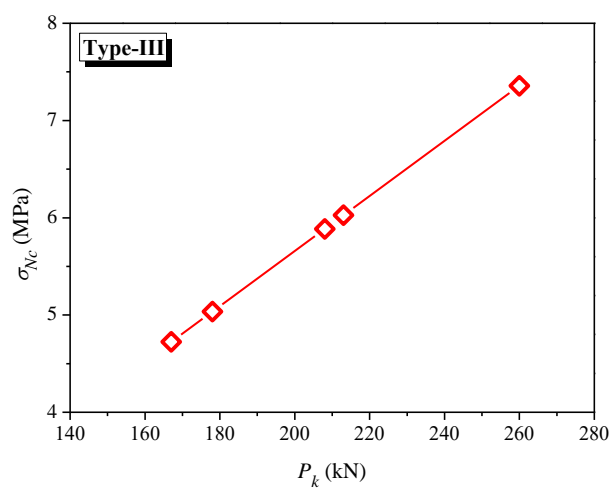

(c)

Figure 10. Variation of $\sigma_{N c}$ with $P_{k}$ for notched samples: (a) Type-I, (b) Type-II, (c) Type-III.

Furthermore, for Type-II, concrete pressure tests were conducted on fractured half samples. Accordingly, it is observed that $f_{c}$ increased linearly with increasing $P_{k} . f_{c}$ values varied between $23 \mathrm{MPa}$ and $32 \mathrm{MPa}$ and $f_{c}$ increased a maximum of $32 \%$ as $P_{k}$ increased (Fig. 11).

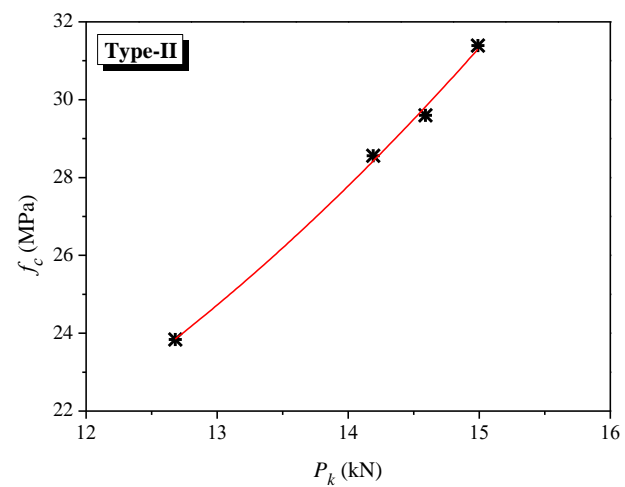

Figure 11. Variation of $f_{c}$ with $P_{k}$ for Type-II. 


\section{Conclusions}

In the present experimental study, $P_{k}, \sigma_{N c}$ and $K_{I c}$ values for different load types of 5 unnotched and 15 notched sample; were determined and the correlation between these parameters was attempted to be expressed with graphs and interpretations. The findings of the study are presented below:

- In the present study, compact pressure samples were analyzed based on the principles of linear elastic fracture mechanics.

- Conducted experiments demonstrated that smaller $P_{k}$ values were observed for samples with more stable loads.

- The present study demonstrated that the standard deviation of the critical fracture parameter $\left(K_{I c}\right)$ of the naturally more stable sample was smaller and the fracture toughness increased with the structure size.

- The correlation between concrete fracture toughness parameters and the compact pressure test was determined.

- The load values which allow the fracture of the relevant sample for Type-I were less than that of the Type-II. Since the sample was mounted on a fixed ground in Type-II, in other words, there was no bottom loading, a higher $P_{k}$ value was required for fracture.

- It was determined that as the fracture load $P_{k}$ on the unnotched sample increased, the splitting tensile strength $\sigma_{N c}$ increased linearly and proportionally. A good fit was observed between $P_{k}$ and $\sigma_{N}$.

- It was observed that there was a linear increase in $P_{k}$ and $K_{I c}$ for Type-I, Type-II and Type-III cases. As the $P_{k}$ increased, the $K_{I c}$ increased at the same rate.

- Higher $P_{k}$ values were measured for Type-III when compared to others and higher $K_{I c}$ values were obtained. These differences were considered to be due to the load pattern.

- In conclusion, it was determined that the Type-II $K_{\text {Ics }}$ were $22 \%$ higher than that of Type-I on average, the Type-III $K_{\text {Ics }}$ were $53 \%$ higher than that of Type-I on average, and Type-III $K_{\text {Ics }}$ were $26 \%$ more than that of Type-II on average.

- It was observed that there was a linear increase in $P_{k}$ and $\sigma_{N c}$ and that there was a good fit between them. For TypeIII, it was determined that $\sigma_{N c}$ values were significantly higher compared to the others.

- Pressure tests conducted with half samples demonstrated that as $P_{k}$ increased, $f_{c}$ increased as well.

\section{Acknowledgements}

The author acknowledges the support of the Scientific and Technological Research Council of Turkey (TUBITAK) PhD Scholarship [grant number 2211-A].

\section{References}

Akkaya, Y., Bayramov, F., and Taşdemir, M.A., 2003. Betonun kırılma mekaniği: tasarımda kullanılan mekanik özellikler ile kırılma parametreleri arasındaki bağıntılar. Türkiye Müh. Haberleri, 426(4).
Barenblatt, G. I., 1959. On equilibrium cracks forming during brittle fracture, Prikladnaya Matematika Mekhanika (PMM), 23, 434-444.

Caglar, Y., 2014. A study on notch and size effect of concrete fracture in mode I, Gazi University, Institute of Science and Technology, PhD Thesis, Ankara, Turkey.

Dugdale, D. S., 1960. Yielding of steel sheets containing slits, J. Mech. Phsy. Solids, 8, 100-104.

Galilei, G., 1933. Discorsi e dimostrazioni matematiche intorno a due nuove scienze, Elzeviri, Leida, 1638. (English translation, two new sciences, The Macmillan Company, N. Y.)

Gettu, R., Saldivar, H., and Kazemi, M.T., 1998. Implications of the size effect method for analysing the fracture behaviour of concrete, Int. J. Solids Structures, 35(31), 4121-4132.

Hilsdorf, H. K., and Brameshuber, W., 1991. Code-type formulation of fracture mechanics concepts for concrete, International Journal of Fracture, 51, 61-72.

Ince R., 2010. Determination of concrete fracture parameters based on two-parameter and size effect models using split-tension cubes, Engineering Fracture Mechanics, 77, 2233-2250.

Ince R., 2012. Determination of concrete fracture parameters based on peak-load method with diagonal split-tension cubes, Engineering Fracture Mechanics, 82, 100-114.

Ince R., Gor M., Eren M.E., and Alyamaç, K.E., 2016. The effect of size on the splitting strength of cubic concrete members, Strain, 51(2), 135-146.

Ince R., Gor M., Alyamac, K.E., and Eren M.E., 2016. Multi-fractal scaling law for split strength of concrete cubes, Magazine of Concrete Research, 68(3), 141-150.

Ince, R., 2017. The fracture mechanics formulas for split-tension strips. Journal of Theoretical and Applied Mechanics, 55(2), 607-619.

Irwin, G. R., 1957. Analysis of stresses and strains near the end of a crack traversing a plate, J. Appl. Mech., 24, 361-364.

Jensen, E.A., and Hansen, W., 2001. Fracture energy test for highway concrete-determining the effect of coarse aggregate on crack propagation resistance, Transportation Res. Record, 1730, 10-16.

Kaplan, M. F., 1961. Crack propagation and the fracture of concrete, Journal of ACI, 58, 591- 610 .

Külcü, H. M., 2015. Identification of fracture toughness for flat and tempered flat soda-lime glass by means of indentation technique, Istanbul Technical University, Institute of Science and Technology, Master Thesis, Istanbul, Turkey.

Rao, G. A., and Prasad, B. K. R., 2002. Fracture energy and softening behaviour of high strength concrete, Cement and Concrete Research, $32,247-252$.

RILEM Technical Committee 50-FMC, 1985. Determination of the fracture energy of mortar and concrete by means of three-point bend tests of notched beams, proposed RILEM draft recommendations, RILEM, Materials and Structures 18(106), 285- 296.

Sabir, B.B., and Asili, M., 1996. Stress Analysis of a fracture test specimen for cementitious materials, Cement and Concrete Composites, 18, 141-151.

Sorucu A., 2007. The determination of crack propagation and fracture toughness in orthotropic materials, Dokuz Eylül University, Institute of Science and Technology, Master Thesis, İzmir, Turkey. 
Tugrul, E., 2016. Betonun kırılma tokluğu parametrelerinin kompakt basınç deneyi ile belirlenmesi, Firat University, Institute of Science and Technology, Doctoral Seminar, Elazig, Turkey, (in Turkish).
Yan, A., Wu, K. R., Zhang, D., and Yao, W., 2001. Effect of fracture path on the fracture energy of high-strength concrete. Cement and Concrete Research, 31(11), 1601-1606. 